\title{
Burden of Talaromyces marneffei infection in people living with HIV/AIDS in Asia during ART era: a systematic review and meta-analysis
}

Yuanyuan Qin ${ }^{1,2+}$, Xiaojie Huang ${ }^{2 \dagger}$, Hui Chen ${ }^{3}$, Xinchao Liư ${ }^{4}$, Yao Li ${ }^{1,2}$, Jianhua Hou ${ }^{2}$, Aixin Li $i^{2}$ Xiaofeng Yan ${ }^{5^{*}}$ and Yaokai Chen ${ }^{1 *}$

\begin{abstract}
Background: Talaromyces marneffei (TM) is a dimorphic fungus mainly prevalent in Southeast Asian countries, which often causes disseminated life-threatening infection. TM infection often occurs in HIV/AIDS patients even in the antiretroviral therapy (ART) era. However, there has as yet, not been a systematic analysis of the prevalence of TM infection in HIV-infected populations in Asia.
\end{abstract}

Methods: In this study, we searched Pubmed, Embase, Web of Science, China National Knowledge Infrastructure (CNKI), and WanFang from inception to 21 November 2018 for studies reporting TM infection in people living with HIV/AIDS (PLWHA). Our meta-analysis included studies investigating the prevalence of TM infection in PLWHA. Reviews, duplicate studies, and animal studies were excluded. A random effects model was used to estimate pooled prevalence, and meta-regression analysis was conducted to explore potential factors for heterogeneity.

Results: 159,064 patients with HIV infection in 33 eligible studies were included in our meta-analysis. The pooled prevalence of TM infection in PLWHA was 3.6\%. Vietnam had the highest prevalence (6.4\%), followed by Thailand (3.9\%), China (3.3\%), India (3.2\%) and Malaysia (2.1\%). In China, TM infection was most prevalent in South China (15.0\%), while the burden in Southwest China was not very heavy (0.3\%). CD4+ T-cell counts below $200 \mathrm{cells} / \mathrm{mm}^{3}$ contributed to the increased risk of TM infection in PLWHA (OR 12.68, 95\%Cl: 9.58-16.77). However, access to ART did not significantly decrease the risk of TM infection in PLWHA.

Conclusions: The burden of TM infection in Asia is heavy, and varies from region to region. PLWHA in lower latitude areas are more likely to suffer from TM infection. Optimization of diagnostic tools and universal screening for TM in vulnerable people to ensure early case detection and prompt antifungal treatment should be considered.

Keywords: HIV/AIDS, Talaromyces marneffei, Prevalence, Meta-analysis

\footnotetext{
* Correspondence: 2429918342@qq.com; yaokaichen@hotmail.com

†Yuanyuan Qin and Xiaojie Huang contributed equally to this work.

${ }^{5}$ Chongqing Public Health Medical Center, Chongqing, China

'Division of Infectious Diseases, Chongqing Public Health Medical Center,

Chongqing, China

Full list of author information is available at the end of the article
}

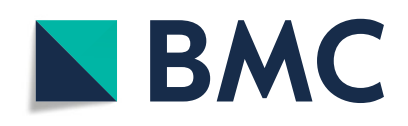

(- The Author(s). 2020 Open Access This article is licensed under a Creative Commons Attribution 4.0 International License, which permits use, sharing, adaptation, distribution and reproduction in any medium or format, as long as you give appropriate credit to the original author(s) and the source, provide a link to the Creative Commons licence, and indicate if changes were made. The images or other third party material in this article are included in the article's Creative Commons licence, unless indicated otherwise in a credit line to the material. If material is not included in the article's Creative Commons licence and your intended use is not permitted by statutory regulation or exceeds the permitted use, you will need to obtain permission directly from the copyright holder. To view a copy of this licence, visit http://creativecommons.org/licenses/by/4.0/. The Creative Commons Public Domain Dedication waiver (http://creativecommons.org/publicdomain/zero/1.0/) applies to the data made available in this article, unless otherwise stated in a credit line to the data. 


\section{Background}

Talaromyces marneffei (TM), previously known as Penicillium marneffei, is a dimorphic and pathogenic fungus that often causes invasive infection in immunocompromised patients. Southeast Asia, South China and Northeast India are the main endemic areas of TM infection, while there are a few case reports outside these endemic areas [1-5]. As an AIDS-defining illness, the prevalence of TM infection has increased significantly in the past decades due to the epidemic of HIV infection $[6,7]$.

TM infection has a higher mortality than most of AIDSrelated illnesses [8] in people living with HIV/AIDS (PLWHA), which ranges from 8 to 40\% [9-12]. The common clinical manifestations in TM infection include fever, weight loss, anemia, weakness, skin lesions, lymphadenopathy and hepatosplenomegaly [13]. Diagnosis of TM infection primarily depends on culture-based methods. Although there have been some highly specific serodiagnostic methods developed, false-negative results remain an obstacle to rapid diagnosis of TM infection [14].

Although TM infection continues to pose a serious public health problem to PLWHA in many world regions, we still do not have a comprehensive understanding of the severity of the issue, since results and data from different studies vary greatly, even when different studies have been conducted in the same country, or in the same endemic area. Furthermore, the impact of ART on the prevalence of TM infection still remains unclear. Previous studies have analyzed the burden of Toxoplasma gondii infection, Cryptosporidium infection and pneumocystis pneumonia [15-17]. However, there has been no meta-analysis on the burden of TM infection in PLWHA thus far. We therefore conducted a systematic review and meta-analysis in this study, aiming to understand the overall burden of the disease in different countries and regions, and the impact of ART on the disease burden.

\section{Methods}

\section{Search strategy and inclusion criteria}

We systematically searched Pubmed, Embase, Web of Science, China National Knowledge Infrastructure (CNKI) and WanFang from inception to 21 November 2018, for research articles published in both the English and Chinese languages. Search terms included "Talaromyces marneffei", "Penicillium marneffei", "marneffei" or "penicilliosis" cross-referenced with "HIV", "AIDS", "human immunodeficiency virus", or "acquired immune deficiency syndrome". We conducted the meta-analysis in accordance with the Preferred Reporting Items for Systematic Reviews and Meta-Analysis (PRISMA) statement. The protocol of our study was registered at the International Prospective Register of Systematic Reviews (PROSPERO registration number: CRD42018115645).
An article was included in our meta-analysis if it satisfied the following criteria: (1) participants were PLWHA; and (2) available data was sufficient to estimate the prevalence of TM infection in PLWHA. We excluded articles if (1) they were reviews, or duplicate studies; (2) research objects were animals; (3) the sample size was less than 50; and (4) the methodology for TM infection diagnosis was not clearly stated. TM infection was diagnosed once Talaromyces marneffei has been isolated from the organs, tissues, blood, bone marrow, or other sterile body fluids by culture. We did not include studies in which subjects were only diagnosed solely by clinical symptoms or by serological testing. All titles and abstracts retrieved were attentively examined by two reviewers (Y-YQ and YL).

\section{Data extraction}

We extracted the following information from each eligible article: name of the first author, publication year, location of the study, study design, sample size, number of TM co-infection individuals, diagnostic methods, and demographic characteristics. Two reviewers (YL and YYQ) extracted the data independently. If there was any disputed finding, we achieved consensus through discussions with another two authors (X-JH and Y-KC). For duplicate data, we made a judgment according to known information about the original author, corresponding author, sample size and sample source.

\section{Quality assessment and publication bias test}

Two authors (J-HH and HC) used the Quality Assessment of Diagnostic Accuracy Studies 2 (QUADAS-2) tool to assess the quality of included articles [18]. We defined some signaling questions for our study according to the QUADAS-2 user guidelines. The item "Was a case-control design avoided?" was substituted by "Was the sample size large enough $(\geq 200)$ ?" in Domain 1 (Patient Selection). The items "Were the index test results interpreted without knowledge of the results of the reference standard?" and "If a threshold was used, was it pre-specified?" were replaced by the item "Was the diagnostic method of TM described?" in Domain 2 (Index Test). The reason for this was that the replaced items were designed for meta-analysis of diagnostic methodologies, whereas we aimed to investigate the prevalence of TM infection. The Domain 3 (Reference Standard) was omitted. In Domain 4 (Flow and Timing), the item "Was there an appropriate interval between index test and reference standard?" was omitted, and the item "Were all participants tested for TM?", replaced the item, "Did all patients receive the same reference standard?". Each item in all included articles was assessed according to the following criteria: high risk of bias, low risk of bias, or unclear (Additional file 1: Fig. S1-S2) [15, 
19]. The symmetry of funnel plots and the Egger test were used to assess the presence of publication and selective reporting bias. A $p$ value of less than 0.10 was considered indicative of statistically significant publication bias.

\section{Statistical analysis}

We calculated the pooled prevalence of TM infection in PLWHA in the included studies. Sub-group analyses were performed based on countries, geographic regions and provinces (only studies in China), latitude, ART eras (excluded studies whose research duration spans the limited ART era and the widespread ART era). Forest plots and heterogeneity analysis were performed by Stata (Version 15.1, Stata Corporation, College Station, TX, USA). Data were entered into ArcGIS (Version 10.2, ESRI Inc., Redlands, CA, USA) to generate maps, which shows the estimated prevalence of TM infection in PLWHA at the national level and provincial level. To measure the association between CD4 counts or ART status and TM infection, we performed meta-analyses of available data using a random- or a fixed-effects method to pool weighted odds ratios (OR) of TM infection risk estimates.

We used Cochran's Q ( $\chi^{2}$ and $p$ values) and the $I^{2}$ statistic to assess the heterogeneity between studies. Random-effects models were used for summary statistics, due to the high heterogeneity $\left(I^{2}>50 \%, p<0.1\right)$ of studies. We performed both univariate meta-regression and multivariate meta-regression to determine the factors contributing to the heterogeneity in the studies. The investigated factors included latitude (studies in areas intersecting the Tropic of Cancer or south of the Tropic of Cancer versus studies in North of the Tropic of Cancer), income levels (low-income countries versus middle-income countries) and publication year. We also analyzed sensitivity in order to determine whether large differences in sample sizes would have a statistically appreciable impact on results, which resulted in the exclusion of one study with a sample size much larger than the rest of the included studies.

\section{Results}

\section{Characteristics of original studies}

Initially, 2026 articles were identified. After deduplicating, 1201 unduplicated articles were obtained. 1121 articles unrelated to this analysis were removed, the remaining 80 articles were examined by full text reading. Among these 80 publications, 47 were excluded for various reasons (Fig. 1). Finally, 33 articles assessing TM infection in HIV-infected individuals, with a total subject population of 159,064 PLWHA, were included in our study. As shown in Table 1, the identified studies were conducted in five countries in Asia. There were 47,644 participants (19 studies) from China; 108,285 participants (7 studies) from Thailand, 2370 participants (3 studies) from Vietnam; 620 participants (3 studies) from India, and 145 participants ( 1 study) from Malaysia (Fig. 1, Table 1). Twenty-five articles were reported in English, and 8 studies were published in Chinese.

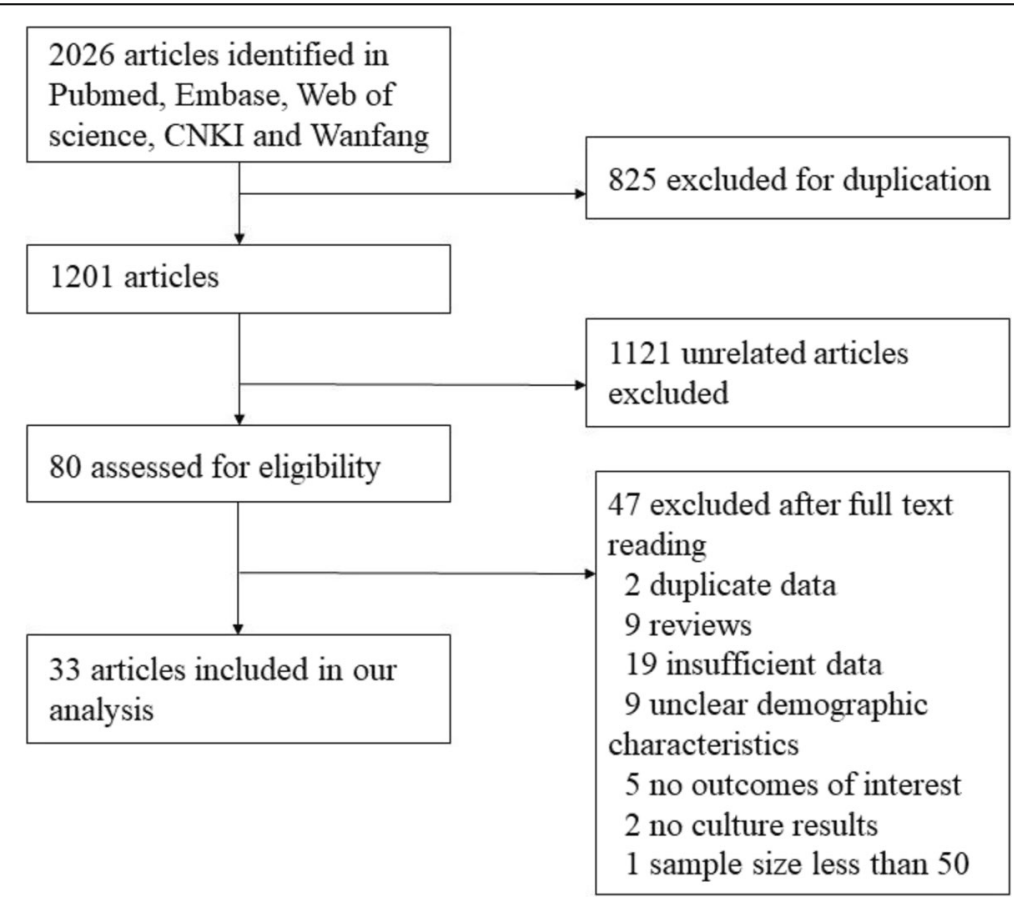

Fig. 1 Flow chart of included studies 
Table 1 The detailed characteristics of included studies

\begin{tabular}{|c|c|c|c|c|c|}
\hline Study & Latitude & Country & No. of TM infection patients & No. of PLWHA & Prevalence \\
\hline Jiang et al. (2018) [8] & Lower & China & 1093 & 6791 & $16.09 \%$ \\
\hline Pang et al. (2018) [20] & Higher & China & 5 & 2298 & $0.22 \%$ \\
\hline Li et al. (2018) [21] & Lower & China & 2 & 200 & $1.00 \%$ \\
\hline Ni et al. (2018) [22] & Higher & China & 8 & 852 & $0.94 \%$ \\
\hline Yen et al. (2017) [23] & Lower & China & 126 & 21,375 & $0.59 \%$ \\
\hline Kaur et al. (2016) [24] & Higher & India & 4 & 280 & $1.43 \%$ \\
\hline Qi et al. (2016) [25] & Higher & China & 43 & 2442 & $1.76 \%$ \\
\hline Zhai et al. (2016) [26] & Higher & China & 2 & 827 & $0.24 \%$ \\
\hline Zheng et al. (2015) [27] & Higher & China & 47 & 981 & $4.79 \%$ \\
\hline Kolalapudi et al. (2014) [28] & Lower & India & 1 & 142 & $0.70 \%$ \\
\hline Son et al. (2014) [9] & Lower & Vietnam & 103 & 2100 & $4.90 \%$ \\
\hline Nguyen et al. (2013) [29] & Lower & Vietnam & 14 & 170 & $8.24 \%$ \\
\hline Xiao et al. (2013) [10] & Higher & China & 12 & 1104 & $1.09 \%$ \\
\hline Han et al. (2013) [30] & Lower & China & 40 & 348 & $11.49 \%$ \\
\hline Su et al. (2012) [31] & Lower & China & 17 & 177 & $9.60 \%$ \\
\hline Xie et al. (2012) [32] & Lower & China & 389 & 3905 & $9.96 \%$ \\
\hline Huang et al. (2011) [33] & Higher & China & 5 & 796 & $0.63 \%$ \\
\hline Huang et al. (2010) [34] & Lower & China & 136 & 762 & $17.85 \%$ \\
\hline Lin et al. (2009) [35] & Lower & China & 18 & 1790 & $1.01 \%$ \\
\hline Zeng et al. (2009) [36] & Lower & China & 19 & 71 & $26.76 \%$ \\
\hline Tang et al. (2009) [37] & Lower & China & 99 & 1559 & $6.35 \%$ \\
\hline Manosuthi et al. (2007) [38] & Lower & Thailand & 1 & 793 & $0.13 \%$ \\
\hline Tang et al. (2007) [39] & Lower & China & 50 & 319 & $15.67 \%$ \\
\hline Sun et al. (2006) [11] & Lower & China & 25 & 1047 & $2.39 \%$ \\
\hline Chierakul et al. (2004) [40] & Lower & Thailand & 57 & 2602 & $2.19 \%$ \\
\hline Louie et al. (2004) [12] & Lower & Vietnam & 7 & 100 & $7.00 \%$ \\
\hline Subsai et al. (2004) [41] & Lower & Thailand & 19 & 155 & $12.26 \%$ \\
\hline Ranjana et al. (2002) [13] & Lower & India & 36 & 198 & $18.18 \%$ \\
\hline Chariyalertsak et al. (2001) [42] & Lower & Thailand & 3054 & 101,945 & $3.00 \%$ \\
\hline Wananukul et al. (1999) [43] & Lower & Thailand & 3 & 91 & $3.30 \%$ \\
\hline Jing et al. (1999) [44] & Lower & Malaysia & 3 & 145 & $2.07 \%$ \\
\hline Tansuphasawadikul et al. (1999) [45] & Lower & Thailand & 50 & 2261 & $2.21 \%$ \\
\hline Supparatpinyo et al. (1994) [1] & Lower & Thailand & 86 & 438 & $19.63 \%$ \\
\hline
\end{tabular}

Publication bias was examined by funnel plots (Fig. 3 in Additional file 2), while statistical significance was assessed by the Egger's regression asymmetry test. There is as yet no indication of significant bias in the measurements $(p=0.889)$.

\section{Prevalence of TM infection in Asian countries}

The prevalence of TM infection in PLWHA reported in the included articles ranged from between 0.13 to $19.63 \%$ in different regions (Table 1). Overall, the estimated pooled prevalence of TM infection in Asia was $3.6 \%$ (95\% CI:2.4-5.4, $n=159,064$ participants, $\mathrm{I}^{2}=98 \%$, $p<0.001)$. The prevalence by country was as follows: 6.4\%(95\%CI: 4.4-9.5) in Vietnam, 3.9\% (95\%CI:1.8-8.3) in Thailand, 3.3\%(95\%CI:1.8-5.8) in China, 3.2\%(95\%CI: $0.3-32.6)$ in India, and 2.1\%(95\%CI:0.7-6.6) in Malaysia, respectively (Fig. 2). The sensitivity analysis showed that our results are stable. After excluding the study of Chariyalertsak et al. [42] with the much larger sample size, the pooled prevalence of TM infection in Asia was 3.6\% (95\%CI: 2.4-5.5, $n=57,119)$. And in Thailand, the pooled prevalence was $3.6 \%$ (95\%CI, $1.2-11.4, n=6340)$.

We also assessed the geographical distribution of TM infection in China. The prevalence of TM infection in 


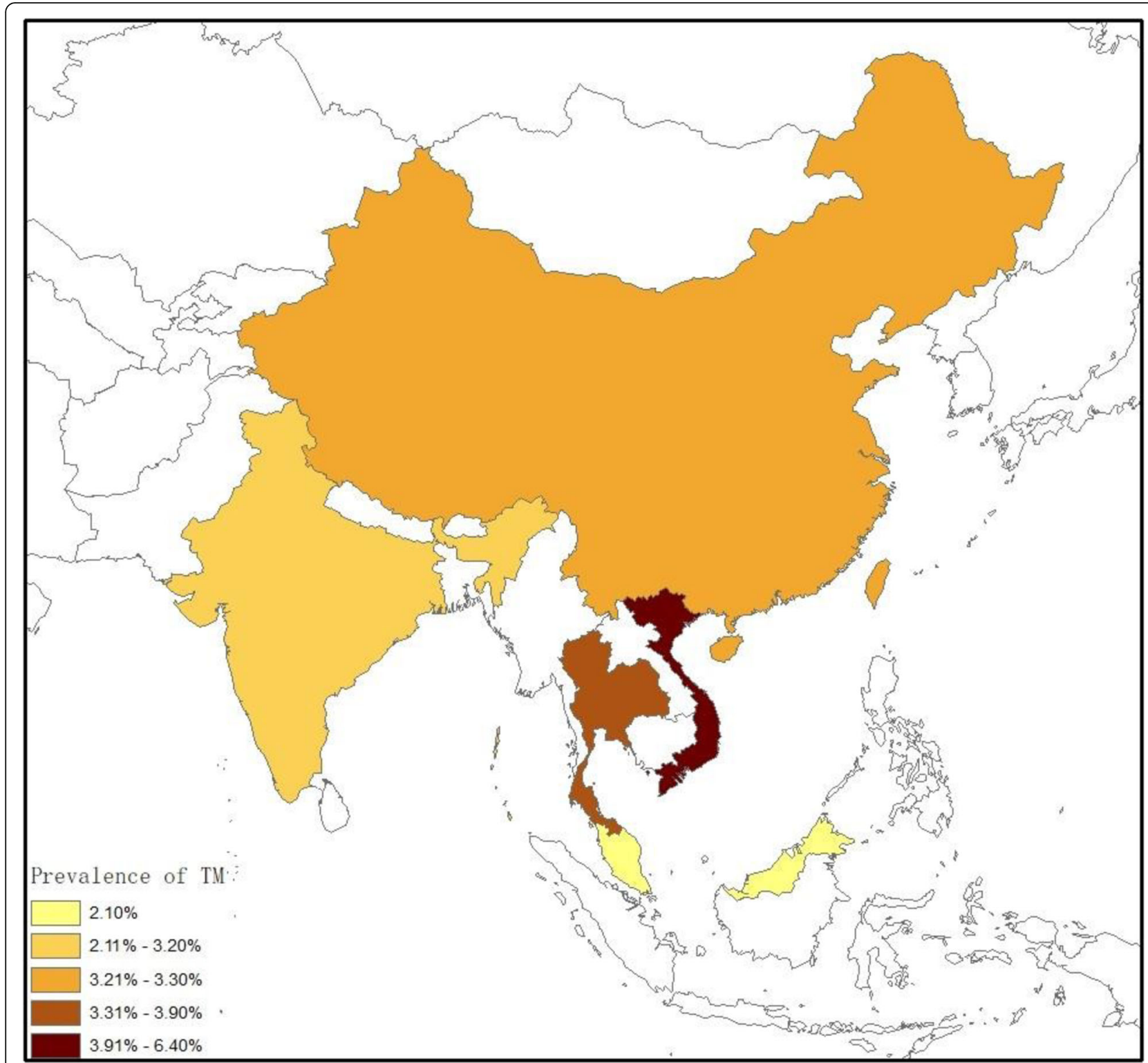

Fig. 2 Prevalence of TM infection in PLWHA in different countries in Asia. Overall, the estimated pooled prevalence of TM infection in Asia was 3.6\% (95\% Cl: $2.4-5.4)$. The prevalence by country was as follows: $6.4 \%$ (95\%Cl: 4.4-9.5) in Vietnam, 3.9\% (95\%Cl: 1.8-8.3) in Thailand, 3.3\% (95\%Cl: 1.8-5.8) in China, 3.2\% (95\% Cl: 0.3-32.6) in India, and 2.1\% (95\%Cl: 0.7-6.6) in Malaysia. Map image is the intellectual property of Esri and is used herein under license. Copyright@ 2019 Esri and its licensors. All rights reserved

PLWHA in China ranged from $0.2 \%$ (95\%CI: $0.1-0.5)$ to 26.5\% (95\%CI: 16.2-43.5\%; Fig. 3). South China had the highest prevalence, estimated at $15.0 \%$ (95\% CI: $11.0-$ 20.4), while Southwest China had the lowest prevalence, estimated at $0.3 \%$ (95\%CI: 0.1-0.9; Fig. 4). Detailed information of these studies is presented in Additional file 3: Table S1.

\section{Prevalence of TM infection in different latitudes}

The sub-group analysis based on different latitudes was performed in 33 studies. As depicted in Fig. 5, The prevalence of $\mathrm{TM}$ infection was $5.5 \%$ (95\%CI:
$3.4-8.7 ; n=149,484)$ in lower latitude regions and 1.0\% (95\%CI: $0.5-2.0 ; n=9580)$ in higher latitude regions. The prevalence of TM infection after excluding the study with the much larger sample size [42] was 5.6\% (95\%CI: $3.5-9.0 ; n=47,539)$ in lower latitude regions and $1.0 \%(95 \% \mathrm{CI}: 0.5-2.0 ; \mathrm{n}=9580)$ in higher latitude regions.

\section{Analysis of data heterogeneity}

We observed substantial heterogeneity $\left(I^{2}=99.2 \%\right.$, $p<0.001$; Table 2) in the included studies. We further analyzed the source of the heterogeneity. Our 


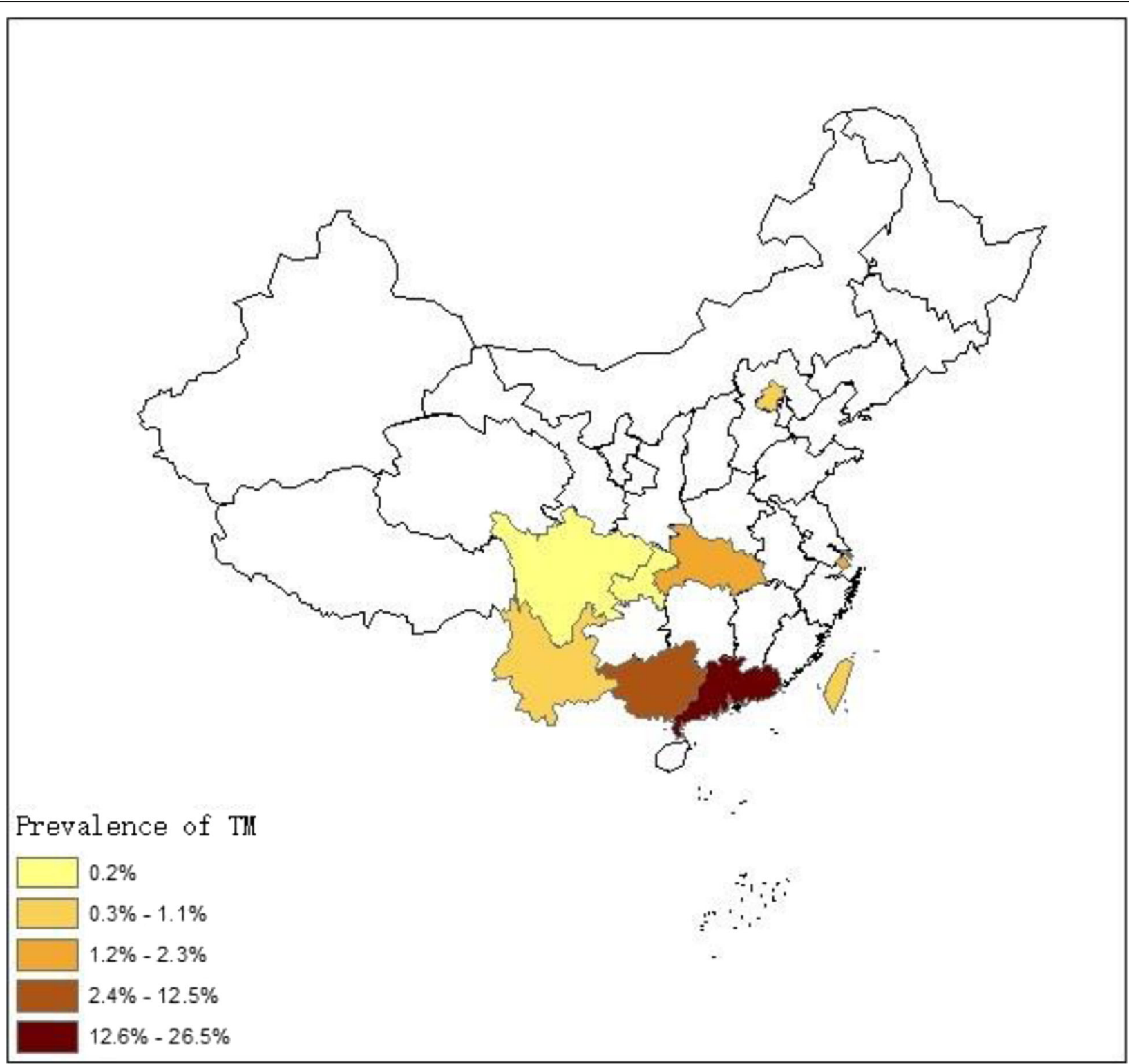

Fig. 3 Prevalence of TM infection in PLWHA in China at the provincial level. Overall, the estimated pooled prevalence of TM infection in China was 3.3\% (95\%Cl:1.8-5.8). The prevalence by province was as follows: $26.5 \%$ (95\%Cl: 16.2-43.5) in Guangdong, $12.5 \%$ (95\%Cl: $8.7-17.9)$ in Guangxi, $1.8 \%$ (95\%Cl: 1.3-2.4) in Shanghai, 1.1\% (95\%Cl: 0.5-2.8) in Taiwan, and 1.0\% (95\%Cl: 0.3-4.1) in Yunnan, 0.9\% (95\%Cl: 0.6-1.5) in Beijing, 0.2\% (95\%Cl: $0.1-1.0)$ in Chongqing and $0.2 \%$ (95\% Cl: $0.1-0.5)$ in Sichuan respectively. Map image is the intellectual property of Esri and is used herein under license. Copyright@ 2019 Esri and its licensors. All rights reserved

univariate meta-regression analyses indicated that latitude (OR 5.616, 95\%CI: 1.941-16.246, $p=0.002$ ) was a source of heterogeneity, and that there was no influence on heterogeneity associated with publication year (OR 0.930, 95\%CI: 0.862-1.004, $p=0.057$ ) and income levels (OR 0.466, 95\%CI: 0.077-2.813, $p=$ 0.393). Subsequently, multivariate meta-regression analysis results showed that latitude was a possible cause of heterogeneity (OR 4.442, 95\%CI: 1.21316.268, $p=0.026$ ).

\section{Prevalence of TM infection in different ART eras}

In this meta-analysis, we divided HIV treatment into two eras: limited ART era (before 2008) and widespread ART era (2008 and thereafter) and compared the prevalence of TM infection in the two different eras. Seven studies were excluded from the sub-group analysis of the different ART eras, because the study period spanned the widespread ART era and the limited ART era. The prevalence of TM infection was $5.2 \%$ (95\%CI: $3.1-8.8 ; n=112,520)$ in limited ART era and $2.5 \%$ 


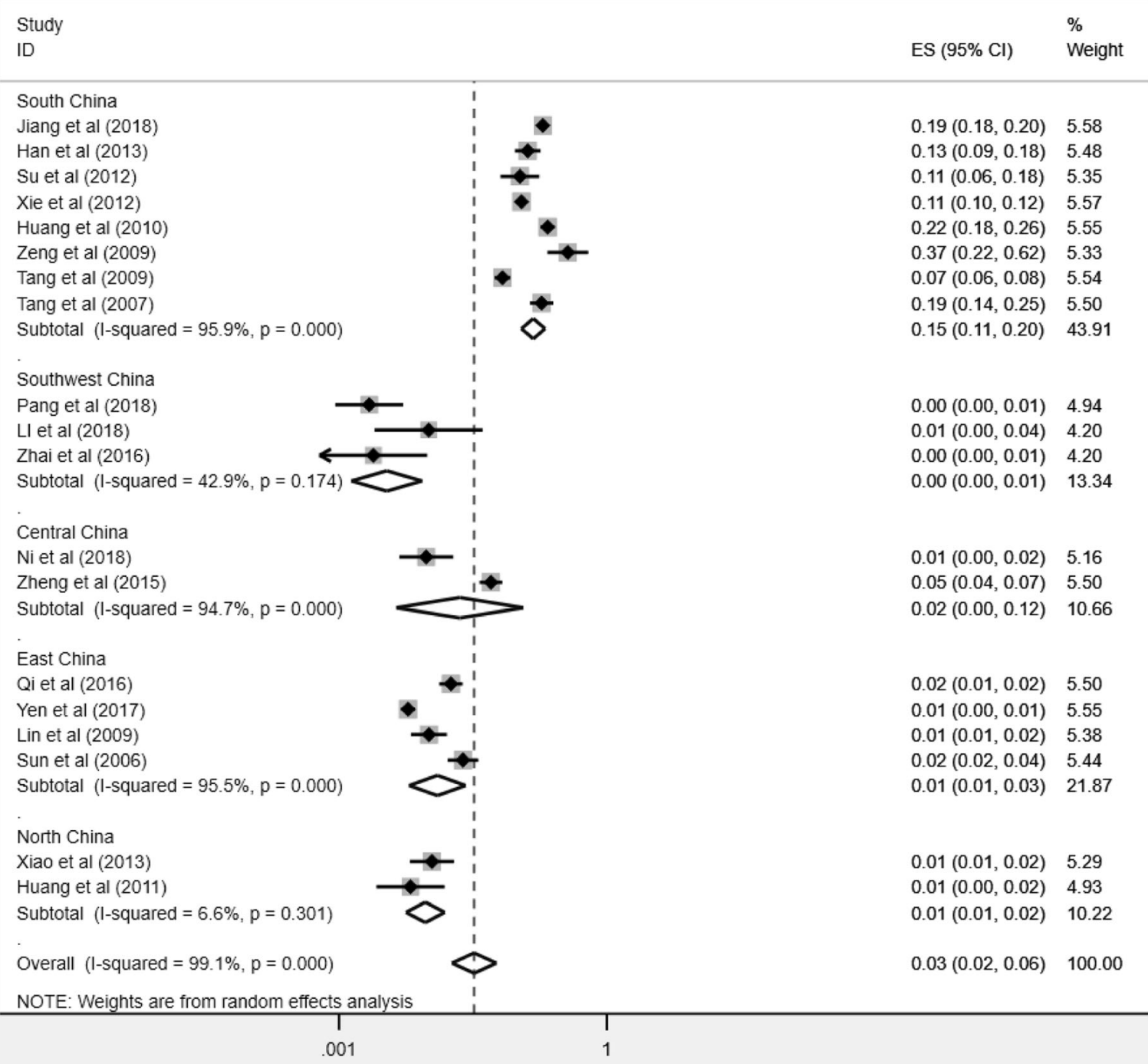

Fig. 4 Pooled prevalence of TM infection in different regions of China. Forest plot shows the estimated prevalence of TM infection in PLWHA in five regions of China with $95 \% \mathrm{Cl}$. Cl = confidence interval; $\mathrm{ES}=$ effect size (the prevalence of TM infection in PLWHA); $P^{2}=P^{2}$ statistic was used to assess the heterogeneity between studies

(95\%CI: $1.4-4.5 ; n=19,086)$ in widespread ART era (Fig. 6); however, we did not observe significant statistical difference in the prevalence of TM infection between the different ART eras (Table 3).

We did perceive the large difference in sample size between the limited-ART era and the widespread-ART era groups, and in order to determine whether the large difference in sample size would have an impact on our results, we further did a sensitivity analysis for comparability, which excluded the study of Chariyalertsak et al. [42] with the large sample size. Subsequent sensitivity analysis showed that our results were stable. The prevalence of TM infection after excluding the study with the much larger sample size was 5.3\% (95\%CI: 2.9-9.8; $n=10,575)$ in limited ART era and 2.5\% (95\%CI: 1.4-4.5; $n=19,086)$ in widespread ART era.

\section{The impact of CD4+ T-cell counts and on-ART treatment on TM infection}

Four studies $(n=7809)$ described the number of PLWHA with CD4+ T-cell counts below 200 cells $/ \mathrm{mm}^{3}$ and the number of PLWHA on ART (Table 4). Our results showed that PLWHA with CD4+ T-cell counts below 200 cells $/ \mathrm{mm}^{3}$ had a higher TM infection 


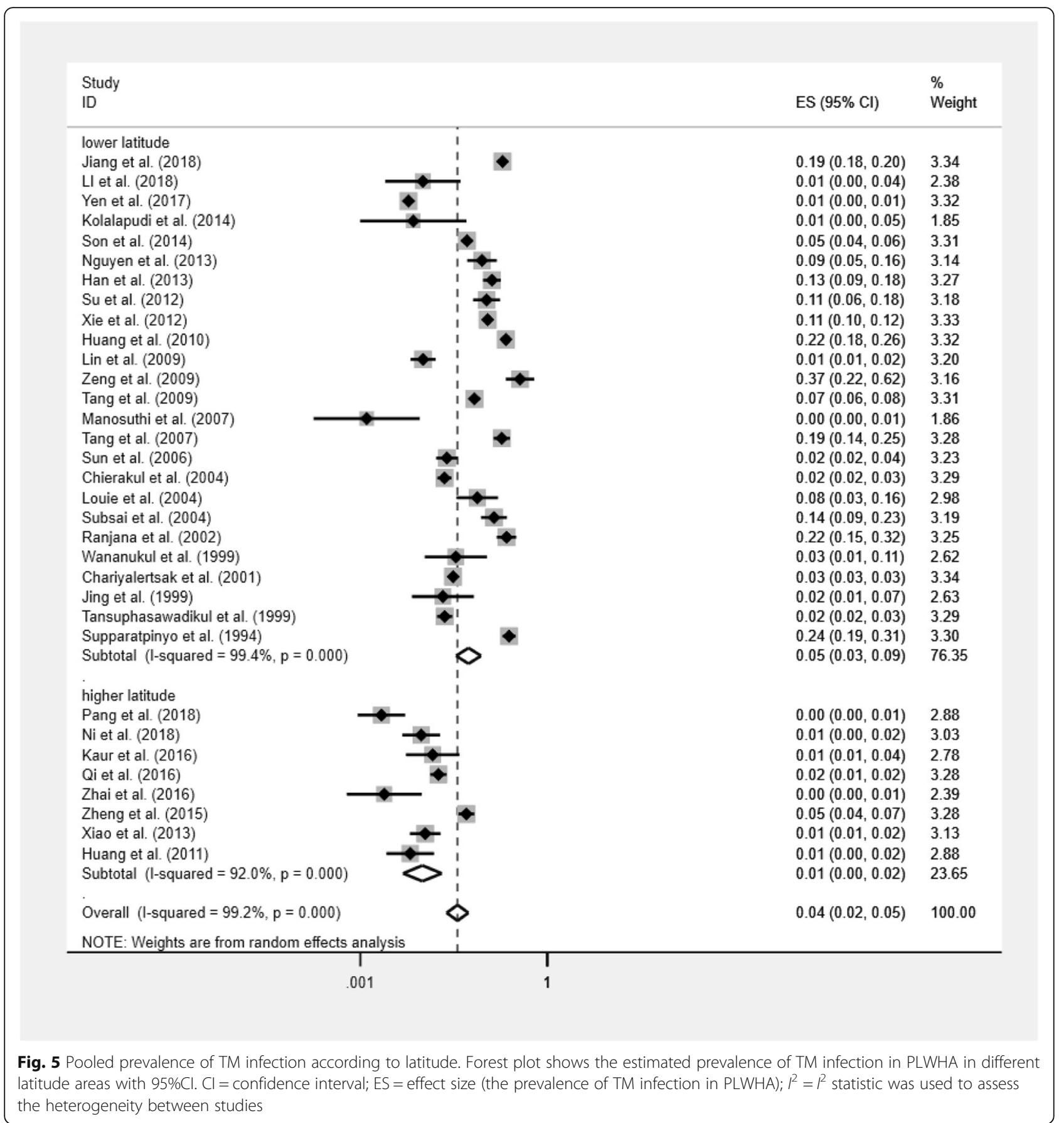

prevalence than those with $\mathrm{CD} 4+\mathrm{T}$-cell counts $\geq 200$ cells $/ \mathrm{mm}^{3}$ (OR 12.68, 95\%CI: 9.58-16.77, Fig. 7). However, there was no statistically significant difference in TM infection prevalence rates between PLWHA on ART and PLWHA not on ART (OR 0.53, 95\%CI: 0.142.01, Fig. 8).

Articles ranked by year of publication. The lower latitude is defined as intersecting the tropic of cancer or south of the tropic of cancer and the higher latitude is defined as north of the tropic of cancer.

\section{Discussion}

Our analysis found that the pooled prevalence of TM infection in Asia was 3.6\%, which appears not as high as expected, compared with the prevalence of Toxoplasma gondii infection and Cryptosporidium infection globally $[15,16]$. However, actual prevalence rates may not be as optimistic as what the results show. Firstly, the diagnosis of TM infection in our included studies was based on culture of clinical specimens, which is considered to be the gold standard for diagnosis of TM infection, but is 
Table 2 The influence of variables on the heterogeneity of prevalence $(n=159,064)$

\begin{tabular}{|c|c|c|c|c|c|c|c|c|c|}
\hline & \multirow{2}{*}{$\begin{array}{l}\text { No. of } \\
\text { study }\end{array}$} & \multirow{2}{*}{$\begin{array}{l}\text { No. of TM infection } \\
\text { patients }\end{array}$} & \multirow{2}{*}{$\begin{array}{l}\text { No. of } \\
\text { PLWHA }\end{array}$} & \multirow{2}{*}{$\begin{array}{l}\text { Prevalence of TM } \\
\text { infection }\end{array}$} & \multicolumn{3}{|c|}{ Heterogeneity } & \multicolumn{2}{|c|}{ Univariate meta-regression } \\
\hline & & & & & $x^{2}$ & $p$ value & $P^{2}$ & OR $(95 \% \mathrm{Cl})$ & $p$ value \\
\hline Latitude & & & & & & & & $\begin{array}{l}5.616(1.941 \text { to } \\
16.246)\end{array}$ & 0.002 \\
\hline Higher & 8 & 126 & 9580 & $1.0 \%(0.5-2.0)$ & 87.65 & 0.000 & $92.0 \%$ & & \\
\hline Lower & 25 & 5448 & 149,484 & $5.5 \%(3.4-8.7)$ & 3960.18 & 0.000 & $99.4 \%$ & & \\
\hline Income level & & & & & & & & $\begin{array}{l}0.466 \text { (0.771 to } \\
2.813)\end{array}$ & 0.393 \\
\hline Low & 3 & 124 & 2370 & $6.4 \%(4.4-9.5)$ & 4.09 & 0.129 & $51.1 \%$ & & \\
\hline Middle & 30 & 5450 & 156,694 & $3.4 \%(2.2-5.2)$ & 4148.53 & 0.000 & $99.3 \%$ & & \\
\hline $\begin{array}{l}\text { Publication } \\
\text { year }\end{array}$ & 33 & 5574 & 159,064 & - & - & - & - & $\begin{array}{l}0.930(0.862 \text { to } \\
1.004)\end{array}$ & 0.057 \\
\hline Total & 33 & 5574 & 159,064 & & & & & & \\
\hline
\end{tabular}

not available in many TM endemic areas [46]. Therefore, patients with TM infection may not be reliably identified in these areas. Secondly, we excluded studies in which patients were diagnosed by serological and molecular methods, because of issues related to the specificity of these methods $[47,48]$. Thirdly, symptoms of TM infection are complex and non-specific, and misdiagnosis and missed diagnosis are not uncommon in clinical practice. As the most populous continent in the world, Asia has approximately 5,900,000 (5100000-7,100,000) PLWHA according to data from UNAIDS from 2018 [49]. Based on our pooled prevalence, the approximate number of PLWHA with TM co-infection may approach 236,000 (102000-355,000), suggesting that the burden of disease inflicted by TM infection is significantly heavy in this region.

Univariate meta-regression on publication year, income level, and latitude were conducted. No statistically significant difference was found in TM infection prevalence among different income level countries in our meta-analysis, suggesting that income level is not a factor in the prevalence of TM infection. This differs from prevalence rates for Toxoplasma gondii infection and Cryptosporidium infection, which was found to be related to differing national income levels $[15,50]$. In our study, both univariate and multivariate meta-regression indicated that latitude may be the main source of heterogeneity. Most lower latitude areas in Asia have a tropical monsoon climate and relatively high temperatures throughout the year. The annual average temperature of those regions is above $22^{\circ} \mathrm{C}$, and the temperature is generally above $16^{\circ} \mathrm{C}$, even in the coldest month. A study by Philips et al. [51] found that TM hospital admission was closely associated with environmental humidity, but not to other environmental variables. This may explain the association between lower latitudes and higher TM prevalence, in that the prevailing climate in Southeast Asia and South China may provide favorable environmental conditions for the growth and spread of TM.

In China, the prevalence of TM infection varied greatly from province to province, with the lowest prevalence in Sichuan (0.22\%) [20], and the highest prevalence in Guangdong (26.76\%) [52]. Overall, the prevalence of TM infection in South China was significantly higher than that in other regions. The lowest monthly temperature in south China averages $10^{\circ} \mathrm{C}$ or above, and the annual precipitation in this region is $1400-2000 \mathrm{~mm}$. In addition to warm and humid weather, some farmers collect livestock excreta as fertilizer, and people also hunt wild bamboo rats for food, and each of these activities may also be a potential pathway for human infection [53, 54].

As reported by researchers in the past, AIDS patients with low baseline CD4+ T-cell counts were more likely to develop new OIs than others $[38,55]$. TM infection is not an exception to this rule. Our study found that patients with CD4+ T-cell counts below 200cells $/ \mathrm{mm}^{3}$ had a higher risk of TM infection.

Notwithstanding the broader coverage of antiretroviral therapy in Asia, we found no significant statistical difference in TM infection prevalence rates in the widespread ART era compared with the limited ART era. In 2003, only 70,000 people in South and Southeast Asia were accepting ART, and by the end of 2008, 565,000 people were accepting ART, which was eight times the number in 2003 [56]. Although ART use is more widespread than in the past, it is far from the $90 \%$ goal set by WHO, which envisions that, by $2020,90 \%$ of people who are HIV infected will be diagnosed, $90 \%$ of people who are diagnosed will be on ART, and $90 \%$ of those who receive ART will be virally suppressed. This may be the principal reason that the difference in TM infection prevalence rates between the two eras was not calculated to be statistically significant in our analysis. Additionally, delayed 


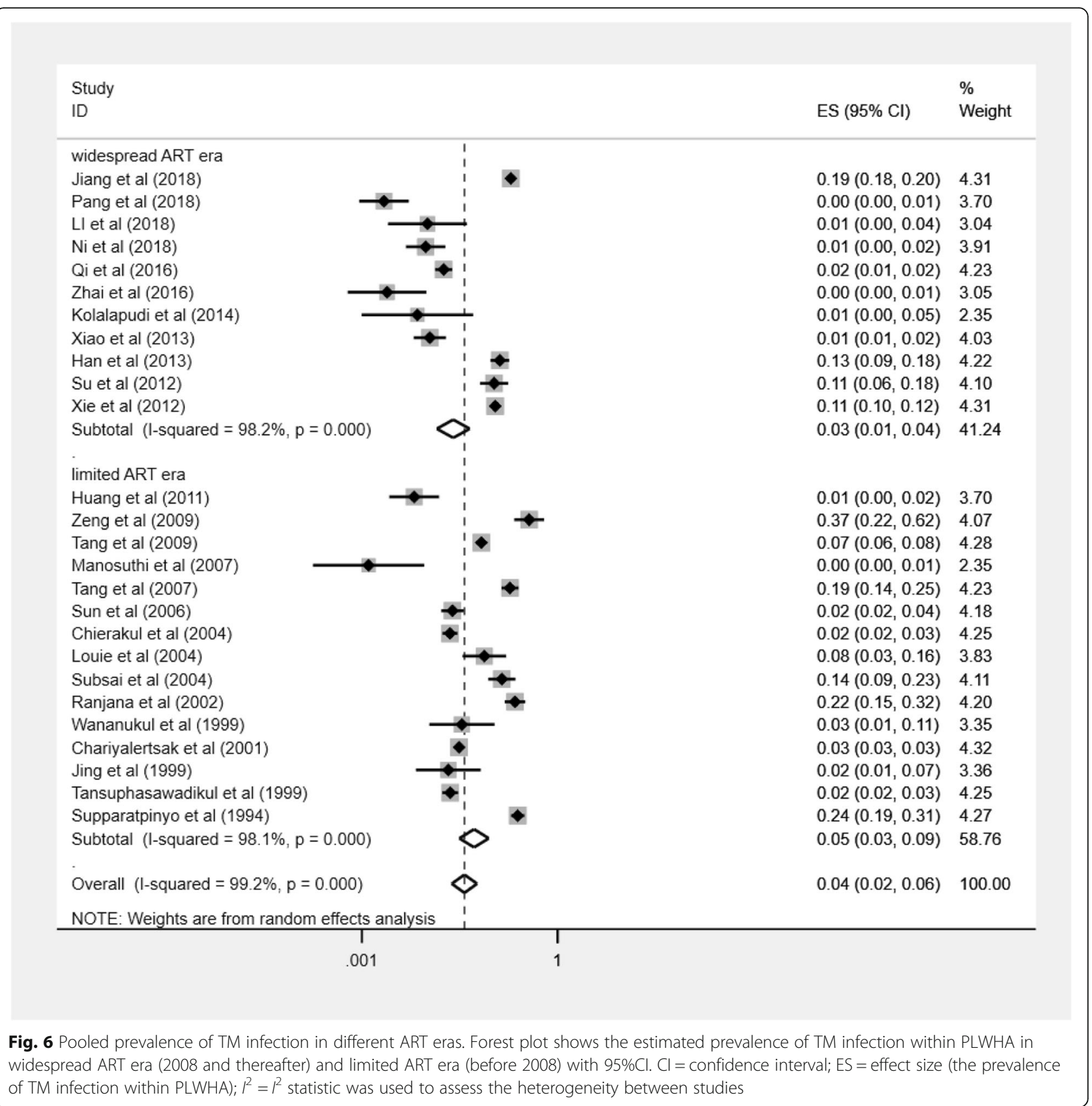

Table 3 The influence of ART eras on the heterogeneity of prevalence $(n=131,606)$

\begin{tabular}{|c|c|c|c|c|c|c|c|c|c|}
\hline & \multirow[t]{2}{*}{$\begin{array}{l}\text { No. of } \\
\text { study }\end{array}$} & \multirow[t]{2}{*}{$\begin{array}{l}\text { No. of TM infection } \\
\text { patients }\end{array}$} & \multirow[t]{2}{*}{$\begin{array}{l}\text { No. of } \\
\text { PLWHA }\end{array}$} & \multirow[t]{2}{*}{$\begin{array}{l}\text { Prevalence of TM } \\
\text { infection }\end{array}$} & \multicolumn{3}{|c|}{ Heterogeneity } & \multicolumn{2}{|l|}{$\begin{array}{l}\text { Univariate meta- } \\
\text { regression }\end{array}$} \\
\hline & & & & & $\overline{x^{2}}$ & $\begin{array}{l}p \\
\text { value }\end{array}$ & $1^{2}$ & OR (95\%Cl) & $p$ value \\
\hline ART era & & & & & & & & $\begin{array}{l}0.453 \\
(0.130 \text { to } 1.578)\end{array}$ & 0.203 \\
\hline Limited & 11 & 3514 & 112,520 & $5.2 \%(3.1-8.8)$ & 727.31 & 0.000 & $98.1 \%$ & & \\
\hline Widespread & 15 & 1612 & 19,086 & $2.5 \%(1.4-4.5)$ & 565.88 & 0.000 & $98.2 \%$ & & \\
\hline
\end{tabular}


Table 4 Influence of CD4 counts and ART treatment on TM infection

\begin{tabular}{|c|c|c|c|c|c|c|c|c|c|c|}
\hline & \multicolumn{2}{|c|}{$C D 4<200$ group } & \multicolumn{2}{|c|}{$C D 4 \geq 200$ group } & \multirow[t]{2}{*}{ OR } & \multicolumn{2}{|l|}{ ART group } & \multicolumn{2}{|c|}{ Without ART group } & \multirow[t]{2}{*}{ OR } \\
\hline & $\begin{array}{l}\mathrm{TM} \\
\text { infection }\end{array}$ & Without TM infection & TM infection & Without TM infection & & TM infection & $\begin{array}{l}\text { Without TM } \\
\text { infection }\end{array}$ & $\begin{array}{l}\mathrm{TM} \\
\text { infection }\end{array}$ & $\begin{array}{l}\text { Without } \\
\text { TM infection }\end{array}$ & \\
\hline Jiang [8] & 873 & 2760 & 52 & 2026 & 12.32 & 393 & 2021 & 700 & 3677 & 1.02 \\
\hline Pang [20] & 5 & 587 & 0 & 362 & 6.79 & 5 & 824 & 0 & 125 & 1.67 \\
\hline Han [30] & 39 & 162 & 1 & 146 & 35.15 & 16 & 243 & 24 & 65 & 0.18 \\
\hline Huang [33] & 5 & 353 & 0 & 438 & 13.64 & 0 & 145 & 5 & 646 & 0.40 \\
\hline
\end{tabular}

diagnosis of HIV infection remains common in this resource-limited region, and this may be another reason for the lack of statistical significance noted above. It is hoped that as ART use gradually becomes more universal in Asia in the future, the prevalence of TM infection will likely decline.

To the best of our knowledge, this is the first systematic review and meta-analysis reporting the burden of TM infection in PLWHA. However, limitations to our meta-analysis should be mentioned. Firstly, our study only included patients diagnosed by TM culture results, and excluded diagnoses by other methods. This may result in underestimation of TM prevalence. Secondly, all data are from East Asia, South Asia and Southeast Asia, and data from other parts of Asia are not available. However, patients are increasingly diagnosed with TM infection outside of epidemic areas after acquiring the fungus during travel within epidemic areas [57]. Thirdly, this study only analyzed articles published in English and Chinese. Research articles published in other languages may have been omitted, which could potentially be a factor that may have resulted in different outcomes.

\section{Conclusions}

Although the prevalence of TM infection in Asia is not exceedingly high, the large population in Asia means that numerous people are still at risk, especially the number of susceptible people in vulnerable sub-

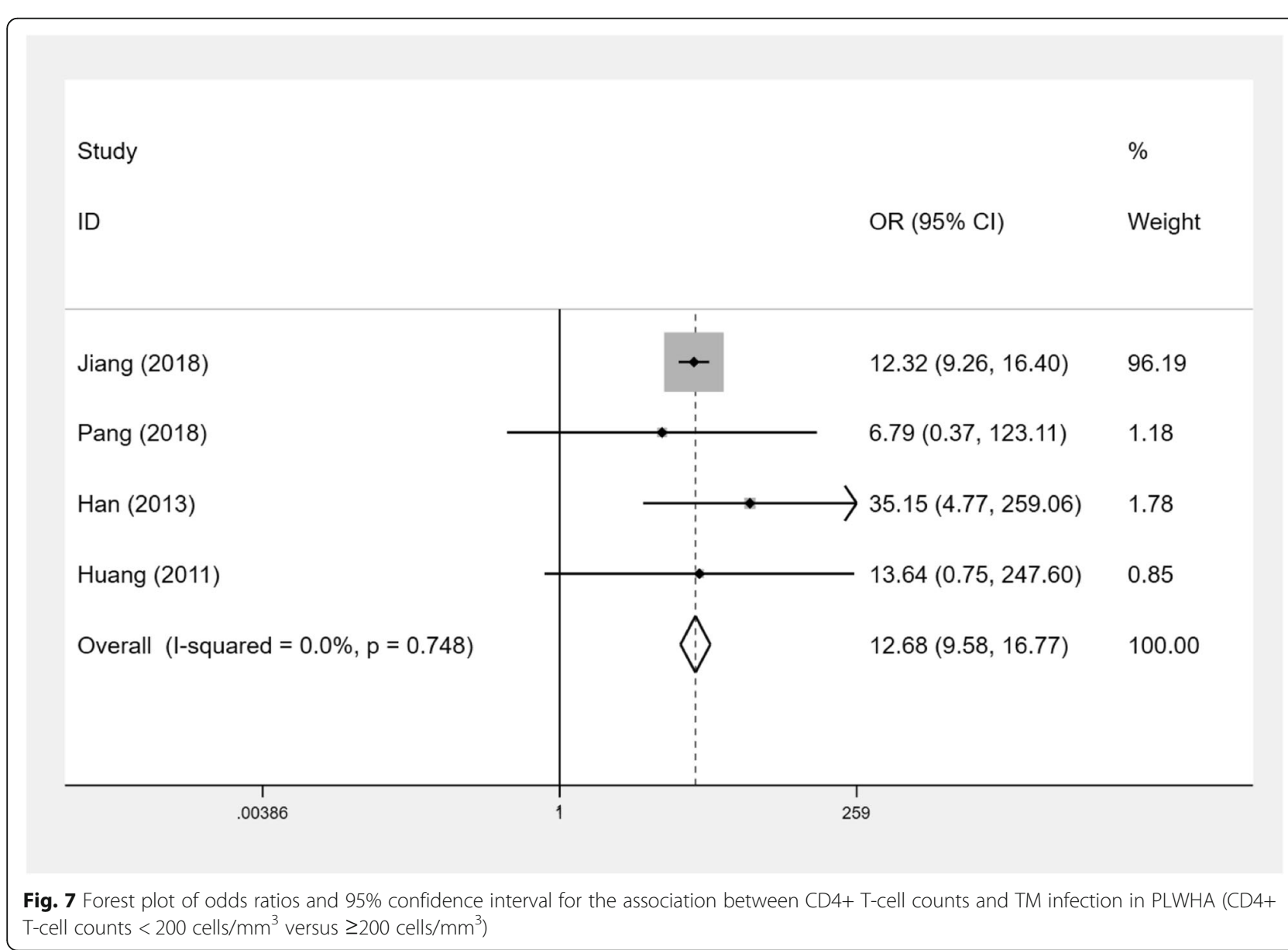




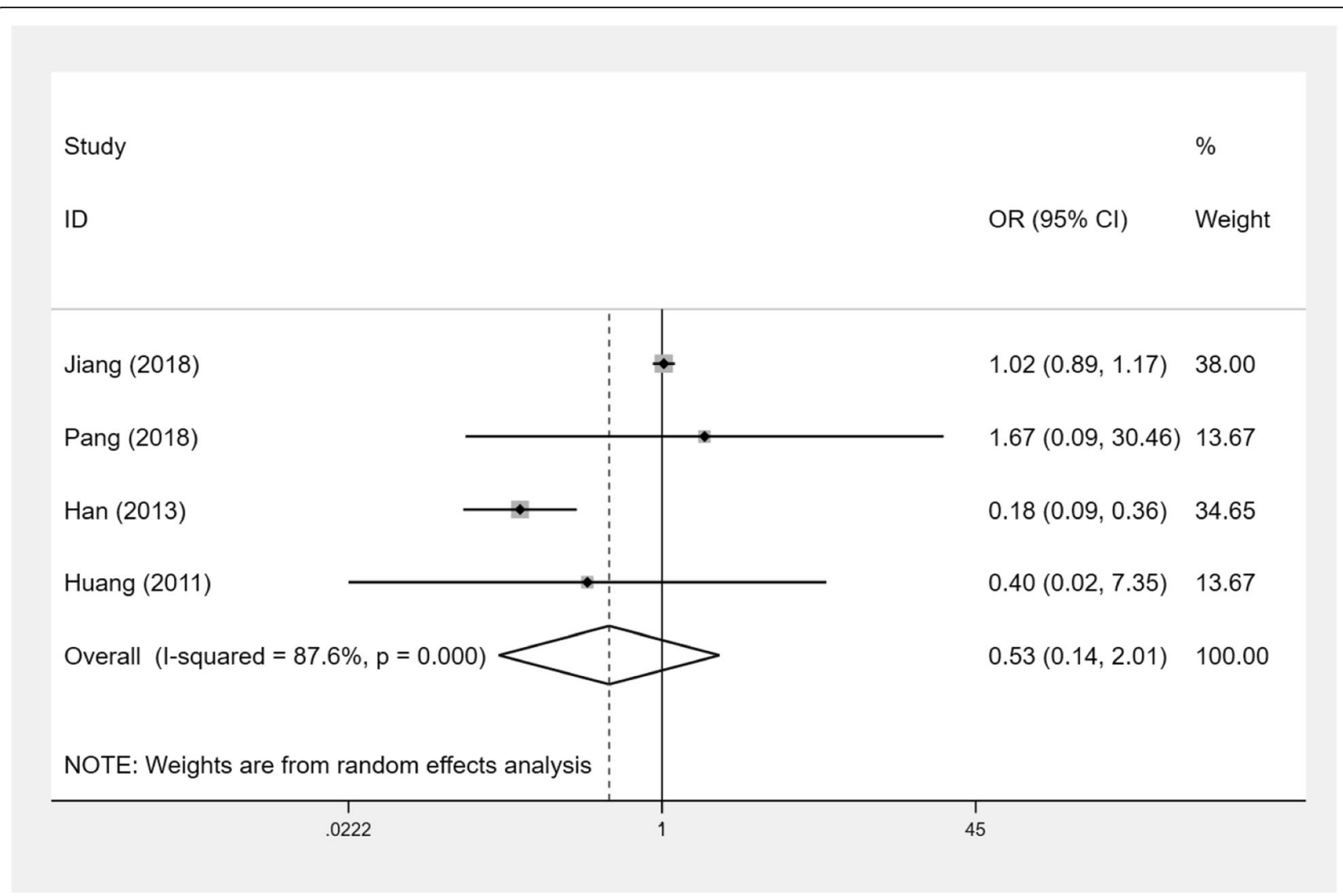

Fig. 8 Forest plot of odds ratios and 95\% confidence interval for the association between ART and TM infection in PLWHA (with ART versus without ART)

populations, e.g. patients with low CD4+ T-cell counts and patients living in endemic areas. Owing to the fact that this fungus poses considerable risk to PLWHA in Asia, our results support the optimization of diagnostic tools and universal screening for TM in vulnerable people to enable early case detection, and thus facilitate prompt, appropriate antifungal treatment.

\section{Supplementary information}

Supplementary information accompanies this paper at https://doi.org/10. 1186/s12879-020-05260-8.

Additional file 1: Fig. S1-S2 showing bias and quality assessment.

Additional file 2: Fig. $\mathbf{S 3}$ showing the funnel plot for publication bias.

Additional file 3: Table S1 showing the prevalence of TM infection in different provinces of China.

\section{Abbreviations}

AIDS: Acquired immunodeficiency syndrome; ART: Antiretroviral therapy; Cl: Confidence interval; CNKI: China National Knowledge Infrastructure; HIV: Human immunodeficiency virus; OR: Odds ratios; PLWHA: People living with HIV/AIDS; PRISMA: Reporting Items for Systematic Reviews and MetaAnalysis; QUADAS-2: Quality Assessment of Diagnostic Accuracy Studies 2; TM: Talaromyces marneffei; UNAIDS: Joint United Nations Programme on HIV/ AIDS; WHO: World Health Organization
Acknowledgements

Not applicable.

\section{Authors' contributions}

$Y-Y Q, X-J H$ and $Y-K C$ designed the study. $Y-Y Q$ and $Y L$ performed the literature search. J-HH and $\mathrm{HC}$ extracted and analyzed the data, and assessed the methodology quality of included studies. Y-YQ, X-JH and A-XL performed the meta-analysis, generated the figures and edited the manuscript with assistance from $\mathrm{Y}-\mathrm{KC}, \mathrm{X}-\mathrm{CL}$, and $\mathrm{X}-\mathrm{FY}$. All authors read and approved the final manuscript.

\section{Funding}

This study was supported by the National Science and Technology Major Project of China during the 13th Five-year plan period (2018ZX10302104, 2017ZX10201101), Major Project of Beijing Municipal Science and Technology Committee (D161100000416003, D171100000517003), the National Natural Science Foundation of China (No. 81701984), Beijing Key Laboratory (BZ0089), 2018 Beijing Youan Hospital Scientific Research Project for Young \& Middle-aged Talent's Cultivation (YNKTTS20180107), and Chongqing Municipal Science and Technology Bureau TCM Key Research Project (ZY201801003). The funders provided financial support for statistical consultation and English editing.

\section{Availability of data and materials}

The datasets used and/or analysed during the current study are available from the corresponding author on reasonable request.

Ethics approval and consent to participate Not applicable. 


\section{Consent for publication}

Not applicable.

\section{Competing interests}

All authors declare that they have no competing interests.

\section{Author details}

'Division of Infectious Diseases, Chongqing Public Health Medical Center, Chongqing, China. ${ }^{2}$ Center for Infectious Diseases, Beijing Youan Hospital, Capital Medical University, Beijing, China. ${ }^{3}$ School of Biomedical Engineering, Capital Medical University, Beijing, China. ${ }^{4}$ Infectious Diseases Department, Peking Union Medical College Hospital, Beijing, China. ${ }^{5}$ Chongqing Public Health Medical Center, Chongqing, China.

\section{Received: 14 August 2019 Accepted: 16 July 2020}

Published online: 29 July 2020

\section{References}

1. Supparatpinyo K, Khamwan C, Baosoung V, Nelson KE, Sirisanthana T. Disseminated Penicillium marneffei infection in Southeast Asia. Lancet. 1994; 344(8915):110-3..

2. Thuy L, Wolbers M, Nguyen HC, Vo MQ, Nguyen TC, Nguyen PHL, Pham SL, Kozal MJ, Shikuma CM, Day JN, et al. Epidemiology, seasonality, and predictors of outcome of AIDS-associated Penicillium marneffei infection in Ho Chi Minh City, Viet Nam. Clin Infect Dis. 2011:52(7):945-52.

3. Gugnani H, Fisher MC, Paliwal-Johsi A, Vanittanakom N, Singh I, Yadav PS. Role of Cannomys badius as a natural animal host of Penicillium marneffei in India. J Clin Microbiol. 2004:42(11):5070-5.

4. Singh PN, Ranjana K, Singh YI, Singh KP, Sharma SS, Kulachandra M, Nabakumar Y, Chakrabarti A, Padhye AA, Kaufman L, et al. Indigenous disseminated Penicillium marneffei infection in the state of Manipur, India: report of four autochthonous cases. J Clin Microbiol. 1999;37(8):2699-702.

5. Deng Z, Ribas JL, Gibson DW, Connor DH. Infections caused by Penicillium marneffei in China and Southeast Asia: review of eighteen published cases and report of four more Chinese cases. Rev Infect Dis. 1988;10(3):640-52.

6. Duong TA. Infection due to Penicillium marneffei, an emerging pathogen: review of 155 reported cases. Clin Infect Dis. 1996;23(1):125-30.

7. Vanittanakom N, Cooper CR Jr, Fisher MC, Sirisanthana T. Penicillium marneffei infection and recent advances in the epidemiology and molecular biology aspects. Clin Microbiol Rev. 2006;19(1):95-110.

8. Jiang J, Meng S, Huang S, Ruan Y, Lu X, Li JZ, Wu N, Huang J, Xie Z, Liang B, et al. Effects of Talaromyces marneffei infection on mortality of HIV/AIDS patients in southern China: a retrospective cohort study. Clin Microbiol Infect. 2019;25(2):233-41.

9. Son VT, Khue PM, Strobel M. Penicilliosis and AIDS in Haiphong, Vietnam: evolution and predictive factors of death. Medecine Et Maladies Infectieuses. 2014;44(11-12):495-501.

10. Xiao J, Gao GJ, Li YM, Zhang W, Tian YF, Huang YX, Su WJ, Han N, Yang D, Zhao HX. Spectrums of Opportunistic Infections and Malignancies in HIVInfected Patients in Tertiary Care Hospital, China. PLoS One. 2013;8(10): e75915.

11. Sun HY, Chen MY, Hsiao CF, Hsieh SM, Hung CC, Chang SC. Endemic fungal infections caused by Cryptococcus neoformans and Penicillium marneffei in patients infected with human immunodeficiency virus and treated with highly active anti-retroviral therapy. Clin Microbiol Infect. 2006;12(4):381-8.

12. Louie JK, Chi NLT, Quang VM, Campbell J, Chau NV, Rutherford GW, Farrar $J$ J, Parry CM. Opportunistic infections in hospitalized HIV-infected adults in Ho Chi Minh City, Vietnam: a cross-sectional study. Int J STD AIDS. 2004; 15(11):758-61.

13. Ranjana KH, Priyokumar K, Singh TJ, Gupta CC, Sharmila L, Singh PN, Chakrabarti A. Disseminated Penicillium marneffei infection among HIVinfected patients in Manipur state, India. J Infect. 2002;45(4):268-71.

14. Ning C, Lai J, Wei W, Zhou B, Huang J, Jiang J, Liang B, Liao Y, Zang N, Cao $C$, et al. Accuracy of rapid diagnosis of Talaromyces marneffei: A systematic review and meta-analysis. PLoS One. 2018;13(4):e0195569.

15. Wang ZD, Wang SC, Liu HH, Ma HY, Li ZY, Wei F, Zhu XQ, Liu Q. Prevalence and burden of Toxoplasma gondii infection in HIV-infected people: a systematic review and meta-analysis. Lancet HIV. 2017;4(4):e177-88.

16. Horman A, Korpela H, Sutinen J, Wedel H, Hanninen ML. Meta-analysis in assessment of the prevalence and annual incidence of Giardia spp. and
Cryptosporidium spp. infections in humans in the Nordic countries. Int J Parasitol. 2004;34(12):1337-46.

17. Wasserman S, Engel ME, Griesel R, Mendelson M. Burden of pneumocystis pneumonia in HIV-infected adults in sub-Saharan Africa: a systematic review and meta-analysis. BMC Infect Dis. 2016;16:482.

18. Whiting PF, Rutjes AW, Westwood ME, Mallett S, Deeks JJ, Reitsma JB, Leeflang MM, Sterne JA, Bossuyt PM, Group Q. QUADAS-2: a revised tool for the quality assessment of diagnostic accuracy studies. Ann Intern Med. 2011;155(8):529-36.

19. Sobanski V, Dauchet L, Lefevre G, Lambert M, Morell-Dubois S, Sy T, Hachulla E, Hatron PY, Launay D, Dubucquoi S. Prevalence of anti-RNA polymerase III antibodies in systemic sclerosis: new data from a French cohort and a systematic review and meta-analysis. Arthritis Rheumatol. 2014;66(2):407-17.

20. Pang W, Shang P, Li Q, Xu J, Bi L, Zhong J, Pei X. Prevalence of opportunistic infections and causes of death among hospitalized HIVinfected patients in Sichuan, China. Tohoku J Exp Med. 2018;244(3):231-42.

21. Li YH, Li Q, Zhai YJ, Li YY, Bai JS, Huang YL, Cao YK. Drug sensitivity study and risk factor analysis of deep fungal infection among HIV/AIDS patients. J Dermatol Venereol. 2018;40(2):168-71.

22. Ni W, Yang L, Liu GZ. Distribution and drug resistance of deep fungus from AIDS patients with infection in hospital of traditional Chinese medicine. China Medical Herald. 2018;15(19):139-42.

23. Yen YF, Chen M, Jen I, Lan YC, Chuang PH, Liu YL, Lee Y, Chen YMA. Association of HIV and opportunistic infections with incident stroke: a Nationwide population-based cohort study in Taiwan. Jaids J Acquired Immune Deficiency Syndromes. 2017;74(2):117-25.

24. Kaur R, Dhakad MS, Goyal R, Bhalla P, Dewan R. Spectrum of opportunistic fungal infections in HIV/AIDS patients in tertiary care hospital in India. Can J Infect Dis Med Microbiol. 2016;2016.

25. Qi T, Zhang R, Shen Y, Liu L, Lowrie D, Song W, Chen J, Wang Z, Shen J, Cai $R$, et al. Etiology and clinical features of 229 cases of bloodstream infection among Chinese HIV/AIDS patients: a retrospective cross-sectional study. Eur J Clin Microbiol Infect Dis. 2016;35(11):1767-70.

26. Zhai ZF, Cheng LJ, Zhou CJ, Song ZQ, Yang H, Shen Z. Facial skin findings are indicators of human immunodeficiency virus infection and acquired immune deficiency syndrome: a retrospective study. J Public Health Heidelberg. 2016;24(6):505-11.

27. Zheng JD, Gui X, Cao Q, Yang RR, Yan YJ, Deng LP, Lio J. A Clinical Study of Acquired Immunodeficiency Syndrome Associated Penicillium marneffei Infection from a NonEndemic Area in China. PLoS One. 2015; 10(6):e0130376.

28. Kolalapudi SA, Guttikonda A. Cutaneous fungal infections in HIV infection: an Indian experience. J Am Acad Dermatol. 2014;70(5):AB108.

29. Nguyen LT, Nguyen MV, Trinh HTX. Etiology of respiratory tract infection in HIV/AIDS patients at the national hospital of tropical diseases (NHTD) Hanoi, Vietnam. Sex Transm Infect. 2013;89(Suppl 1):A95-A95.

30. Han J, Lun WH, Meng ZH, Huang K, Mao Y, Zhu W, Lian S. Mucocutaneous manifestations of HIV-infected patients in the era of HAART in Guangxi Zhuang autonomous region, China. J Eur Acad Dermatol Venereol. 2013; 27(3):376-82.

31. Su GS, Wei SQ, Luo XL, Xie N, Li JY. Opportunistic infection of HIV/AIDS patients in Nanning: clinical analysis of 177 cases. Guangxi Med J. 2012; 34(8):1000-1.

32. Xie N. Distribution of pathogens in blood culture of 3905 AIDS patients. Hainan Med J. 2012;23(9):89-91.

33. Huang XJ, Li HY, Chen DX, Wang XC, Li ZC, Wu YS, Zhang T, Gao YQ, Wu H. Clinical analysis of skin lesions in 796 Chinese HIV-positive patients. Acta Derm Venereol. 2011;91(5):552-6.

34. Huang LF, Tang XP, Cai WP, Chen XJ, Lei CL, Li LH, Zhang FC. An analysis of opportunistic infection in 762 inpafients with human immunodeficiency virus infection in Guangdong areas. Chin J Intern Med. 2010;49(8):653-6.

35. Lin CY, Sun HY, Chen MY, Hsieh SM, Sheng WH, Lo YC, Hung CC, Chang SC. Aetiology of cavitary lung lesions in patients with HIV infection. Hiv Medicine. 2009;10(3):191-8.

36. Zeng CH, Xie T, Li XQ, Liu CD, Li J, Zeng LJ, Shen SJ. Investigation and analysis of fungal infection in patients with HIV/AIDS. South China J Prev Med. 2009;35(2):46-47,50.

37. Tang GL, Liu AM, Li SP, Tang LS. Penicilliosis marneffei in people with HIV/ AIDS: analysis of 99 cases. Ch in J Misdiagn. 2009;9(7):1652-3. 
38. Manosuthi W, Chaovavanich A, Tansuphaswadikul S, Prasithsirikul W Inthong Y, Chottanapund S, Sittibusaya C, Moolasart V, Termvises P, Sungkanuparph S. Incidence and risk factors of major opportunistic infections after initiation of antiretroviral therapy among advanced HIVinfected patients in a resource-limited setting. J Infect. 2007:55(5):464-9.

39. Tang ZR, Lu ZZ, Liu W, Chen J, Hu YY, Deng XE, Liang WX, Yang JY, Lu GG. Treatment of AIDS patients with Penicilliosis marneffei in Guangxi. Applied Prev Med. 2007;01:28-30.

40. Chierakul W, Rajanuwong A, Wuthiekanun V, Teerawattanasook N, Gasiprong M, Simpson A, Chaowagul W, White NJ. The changing pattern of bloodstream infections associated with the rise in HIV prevalence in northeastern Thailand. Trans R Soc Trop Med Hyg. 2004;98(11):678-86.

41. Subsai K, Kanoksri S, Siwaporn C, Helen L. Neurological complications in AIDS patients: the 1-year retrospective study in Chiang Mai University, Thailand. Eur J Neurol. 2004;11(11):755-9.

42. Chariyalertsak S, Sirisanthana T, Saengwonloey O, Nelson KE. Clinical presentation and risk behaviors of patients with acquired immunodeficiency syndrome in Thailand, 1994-1998: regional variation and temporal trends. Clin Infect Dis. 2001;32(6):955-62.

43. Wananukul S, Thisyakorn U. Mucocutaneous manifestations of HIV infection in 91 children born to HIV-seropositive women. Pediatr Dermatol. 1999; 16(5):359-63.

44. Jing W, Ismail R. Mucocutaneous manifestations of HIV infection: a retrospective analysis of 145 cases in a Chinese population in Malaysia. Int J Dermatol. 1999;38(6):457-63.

45. Tansuphasawadikul S, Amornkul PN, Tanchanpong C, Limpakarnjanarat K, Kaewkungwal J, Likanonsakul S, Eampokalap B, Naiwatanakul T, Kitayaporn D, Young NL, et al. Clinical presentation of hospitalized adult patients with HIV infection and AIDS in Bangkok, Thailand. J Acquir Immune Defic Syndr. 1999;21(4):326-32.

46. Limper AH, Adenis A, Le T, Harrison TS. Fungal infections in HIV/AIDS. Lancet Infect Dis. 2017;17(11):e334-43.

47. Lu S, Li X, Calderone R, Zhang J, Ma J, Cai W, Xi L. Whole blood nested PCR and real-time PCR amplification of Talaromyces marneffei specific DNA for diagnosis. Med Mycol. 2016;54(2):162-8.

48. Hien HTA, Thanh TT, Thu NTM, Nguyen A, Thanh NT, Lan NPH, Simmons C, Shikuma C, Chau NW, Thwaites G, et al. Development and evaluation of a real-time polymerase chain reaction assay for the rapid detection of Talaromyces marneffei MP1 gene in human plasma. Mycoses. 2016;59(12): 773-80.

49. Global HIV \& AIDS statistics - 2019 fact sheet. Available from: https://www. unaids.org/sites/default/files/media_asset/UNAIDS_FactSheet_en.pdf. Accessed 26 Sept 2019.

50. Wang ZD, Liu Q, Liu HH, et al. Prevalence of Cryptosporidium, microsporidia and Isospora infection in HIV-infected people: a global systematic review and meta-analysis. Parasit Vectors. 2018;11(1):28.

51. Bulterys PL, Le T, Quang VM, Nelson KE, Lloyd-Smith JO. Environmental predictors and incubation period of AIDS-associated penicillium marneffei infection in Ho Chi Minh City, Vietnam. Clin Infect Dis. 2013;56(9):1273-9.

52. Changhong Zeng TX, Li X, Liu C, Li J, Zeng L, Shen S. Investigation and analysis of HIV/AIDS complicated with fungal infection. South China J Prev Med. 2009;35(2):46-50.

53. Hu Y, Zhang J, Li X, Yang Y, Zhang Y, Ma J, Xi L. Penicillium marneffei infection: an emerging disease in mainland China. Mycopathologia. 2013; 175(1-2):57-67.

54. Li Y, Lin Z, Shi X, Mo L, Li W, Mo W, Yang Z. Retrospective analysis of 15 cases of Penicillium marneffei infection in HIV-positive and HIV-negative patients. Microb Pathog. 2017;105:321-5.

55. Chariyalertsak S, Supparatpinyo K, Sirisanthana T, Nelson KE. A controlled trial of itraconazole as primary prophylaxis for systemic fungal infections in patients with advanced human immunodeficiency virus infection in Thailand. Clin Infect Dis. 2002;34(2):277-84.

56. Towards universal access: Scaling up priority HIV/AIDS interventions in the health sector. Available from: https://www.who.int/hiv/pub/tuapr_2009_en. pdf?ua=1. Accessed 26 Sept 2019.

57. Antinori S, Gianelli E, Bonaccorso C, Ridolfo AL, Croce F, Sollima S, Parravicini C. Disseminated Penicillium marneffei infection in an HIV-positive Italian patient and a review of cases reported outside endemic regions. J Travel Med. 2006;13(3):181-8.

\section{Publisher's Note}

Springer Nature remains neutral with regard to jurisdictional claims in published maps and institutional affiliations.

\section{Ready to submit your research? Choose BMC and benefit from:}

- fast, convenient online submission

- thorough peer review by experienced researchers in your field

- rapid publication on acceptance

- support for research data, including large and complex data types

- gold Open Access which fosters wider collaboration and increased citations

- maximum visibility for your research: over $100 \mathrm{M}$ website views per year

At BMC, research is always in progress.

Learn more biomedcentral.com/submissions 